\title{
Bowel Dysfunction and Colon Transit Time in Brain-Injured Patients
}

\author{
Yu Hyun Lim, M.D., Dong Hyun Kim, M.D., Ph.D. ', Moon Young Lee, M.D., Ph.D. ${ }^{2}$, Min Cheol Joo, M.D.
}

\begin{abstract}
Department of Rehabilitation Medicine and Institute of Wonkwang Medical Science, Wonkwang University School of Medicine, Iksan 570-749, 'Department of Rehabilitation Medicine, Hallym University College of Medicine, Kangdong Sacred Heart Hospital, Seoul 134-701, ${ }^{2}$ Department of Physiology, Wonkwang University School of Medicine, Iksan 570-749, Korea
\end{abstract}

Objective To report the defecation patterns of brain-injured patients and evaluate the relationship between functional ability and colon transit time (CTT) in stroke patients.

Method A total of 55 brain-injured patients were recruited. Patient interviews and medical records review of pattern of brain injury, anatomical site of lesion, bowel habits, constipation score, and Bristol scale were conducted. We divided the patients into constipation $(n=29)$ and non-constipation $(n=26)$ groups according to Rome II criteria for constipation. The CTTs of total and segmental colon were assessed using radio-opaque markers Kolomark ${ }^{\circledR}$ and functional ability was evaluated using the functional independence measure (FIM).

Results Constipation scores in constipation and non-constipation groups were 7.32 \pm 3.63 and 5.04 \pm 2.46 , respectively, and the difference was statistically significant. The CTTs of the total colon in both groups were $46.6 \pm 18.7$ and $32.3 \pm 23.5 \mathrm{~h}$, respectively. The CTTs of total, right, and left colon were significantly delayed in the constipation group $(\mathrm{p}<0.05)$. No significant correlation was found between anatomical location of brain injury and constipation score or total CTT. Only the CTT of the left colon was delayed in the patient group with pontine lesions $(\mathrm{p}<0.05)$.

Conclusion The constipation group had significantly elevated constipation scores and lower Bristol stool form scale, with prolonged CTTs of total, right, and left colon. In classification by site of brain injury, we did not find significantly different constipation scores, Bristol stool form scale, or CTTs between the groups with pontine and suprapontine injury.

Key Words Bowel dysfunction, Colon transit time, Brain injury

Received August 26, 2011; Accepted April 27, 2012

Corresponding author: Min Cheol Joo

Department of Rehabilitation Medicine and Institute of Wonkwang Medical Science, 895 Muwang-ro, Iksan 570-749, Korea

Tel: +82-63-859-1621, Fax: +82-63-843-1385, E-mail: mcjoo68@wku.ac.kr (c) This is an open-access article distributed under the terms of the Creative Commons Attribution Non-Commercial License (http:// creativecommons.org/licenses/by-nc/3.0) which permits unrestricted noncommercial use, distribution, and reproduction in any medium, provided the original work is properly cited.

Copyright $\odot 2012$ by Korean Academy of Rehabilitation Medicine

\section{INTRODUCTION}

Common gastrointestinal disorders among braininjured patients include feeding disorder, constipation, and fecal incontinence. Among those disorders, bowel dysfunction due to neurogenic bowel is one of the most common complications observed among $30-60 \%^{1,2}$ of brain-injured patients. Anxiety related to this disorder becomes a major reason for reduced quality of life, mak- 
ing it difficult to participate in social life and limiting daily activities. However, the importance of gastrointestinal problems in brain-injured patients is overlooked, and there are few reports on assessment of bowel function and colon motility in brain-injured patients.

Previous studies ${ }^{3}$ on constipation in brain-injured patients have examined the frequency of defecation and the patient's subjective symptoms, and objective changes of colonic motility are not represented. Considering previous reports ${ }^{4}$ that the patients sometimes do not have a clear memory of the bowel habits and the low level of correlation between the frequency of defecation and colon transit time (CTT), bowel function in brain-injured patients requires an objective assessment of colonic motility. One of the methods available to objectively assess colonic motility is to measure CTT, which has previously been reported in an examination of spinal cord injury patients and cerebral palsy patients ${ }^{5-7}$ and acute stroke patients. ${ }^{8}$ The CTT were delayed in SCI, cerebral palsy and acute stoke patients. The general concept of constipation has been defined based on the frequency of defecation such as a patient that passes stool less than 3 times per week but the definition has been modernized by the Rome II criteria for functional constipation. ${ }^{9}$ Rome II criteria recommends a diagnosing constipation by assessing the hardness of stool, the sensation of incomplete evacuation, and straining, in addition to the frequency of defecation.

In this study, we divided brain-injured patients into constipation and non-constipation groups using the Rome II criteria, and compared the differences in constipation scores, Bristol stool form scale, and CTT between the 2 groups, and examined the correlation between the site of brain injury, cognitive and physical functional ability, and CTT.

\section{MATERIALS AND METHODS}

\section{Subjects}

From January 2009 to December 2010, a total of 607 patients were admitted due to hemorrhagic stroke, ischemic stroke, or traumatic brain injury to the department of rehabilitation medical treatment in Wonkwang University hospital, Iksan. The study enrolled 55 patients for participation in a survey about defecation patterns and for CTT measurements. Among the brain-injured patients, those who had a history of organic diseases of the gastrointes- tinal tract and those who had a history of gastrointestinal tract operation other than simple appendectomy or simple cholecystectomy were excluded.

A total of 37 male patients and 18 female patients were included, and ages ranged from 21 to 80 years with the average age $61.1 \pm 14.1$ years. The time from the event of the brain injury to participating in the survey and undergoing CTT examinations was an average of 11.1 17.5 months. As for the type of brain injury, 33 patients had ischemic stroke, 20 patients had hemorrhagic stroke, and 2 patients had other kinds of injuries. As for the location, 29 had injury to the right cerebral hemisphere, 19 had injury to the left cerebral hemisphere, and 7 had injury to bilateral cerebral hemispheres. The sites of brain injury were divided into pontine and suprapontine. Ten patients had pontine lesions, 45 had suprapontine; the suprapontine lesions were subdivided into fronto-parietal, temporo-occipital, basal ganglia, thalamus, or multiple lesions (Table 1).

\section{Methods}

Criteria for constipation: We used the Rome II criteria, formed by a multi-nation consensus in 1999, as the criteria for constipation. According to these criteria, constipation was defined when a patient had at least 2 symptoms among 6 items. The items included; straining when defecating $25 \%$ or more of the time, hard stools $25 \%$ or more of the time, sensation of incomplete evacuation $25 \%$ or

Table 1. General Characteristics of Patients with Brain Injury

\begin{tabular}{|c|c|c|}
\hline \multicolumn{2}{|c|}{ Demographic factor } & Value \\
\hline \multicolumn{2}{|c|}{ Total number of cases } & 55 \\
\hline \multicolumn{2}{|l|}{ Mean age (years) } & $61.1 \pm 14.1$ \\
\hline \multicolumn{2}{|c|}{ Sex (male/female) } & $37 / 18$ \\
\hline \multicolumn{2}{|c|}{ Duration of brain injury (months) } & $11.1 \pm 17.5$ \\
\hline \multicolumn{2}{|c|}{$\begin{array}{l}\text { Type of brain injury } \\
\text { (infarction/hemorrhage/etc) }\end{array}$} & $33 / 20 / 2$ \\
\hline \multicolumn{2}{|c|}{ Site of brain injury (suprapontine/pontine) } & $45 / 10$ \\
\hline \multirow[t]{5}{*}{ Suprapontine } & Fronto-parietal & 5 \\
\hline & Temporo-occipital & 7 \\
\hline & Basal ganglia & 24 \\
\hline & Thalamus & 6 \\
\hline & Multiple & 3 \\
\hline Pontine & & 10 \\
\hline
\end{tabular}

Values are number or mean \pm standard deviation 
more of the time, sensation of anorectal obstruction $25 \%$ or more of the time, need for manual maneuvers to facilitate defecation $25 \%$ or more of the time, and defecation 3 times less per week, and patients who belong to this are classified as a constipation group.

Constipation score: The constipation score was ranked from 0 to 3 for each of the 6 items of the Rome II criteria, and the total score was calculated by combining the scores for each item. This method is the same as what used in many previous studies. ${ }^{10}$ In the items of straining in defecation, hard stools, sensation of incomplete evacuation, sensation of anorectal obstruction, and need for manual maneuvers to facilitate defecation, a score of 0 was given for no, a score of 1 for minimum once per 4 bowel movements, score of 2 for 2-3 times per 4 bowel movements, and a score of 3 for always; and for frequency of defecation 3 times less per week, a score of 0 was given for defecation $\geq 3$ times per week, a score of 1 for 1-2 times per week, a score of 2 for defecation once in 10 days, and a score of 3 for hard to defecate for over 10 days. The constipation score ranged from 0 to 18, and the higher score indicated a more severe constipation.

Stool form characteristics: In order to examine the stool form characteristics, we evaluated the macroscopic form of stools according to the Bristol stool form scale, which classifies stool as type 1-7 according to its hardness and form (Table 2). ${ }^{11}$

Colon transit time: In order to measure CTT to assess colonic motility, we administered 1 capsule of Kolomark ${ }^{\circledR}$ (MI Tech, Seoul, Korea) containing 20 radiopaque marker rings at 9 AM daily for 3 days and conducted plain supine abdominal radiography at the same time on the 4th day. As Arhan et al. ${ }^{12}$ described for abdominal radiography, we subdivided the total colon into 3 parts, right colon, left colon, and rectosigmoid colon for measuring the segmental CTT, and calculated total and segmental CTTs with observed markers $\times 1.2$.

Table 2. Bristol Stool Form Scale

Type 1 Separate hard lumps, like nuts

Type 2 Sausage-shaped but lumpy

Type 3 Like a sausage or snake but with cracks on its surface

Type 4 Like a sausage or snake, smooth and soft

Type 5 Soft blobs with clear-cut edges

Type 6 Fluffy pieces with ragged edges, a mushy stool

Type 7 Watery, no solid pieces
Assessment of cognitive and physical functional ability: In order to assess the functional ability of patients, we used the functional independence measure (FIM), and to assess cognitive functional ability we conducted Korean mini-mental status examinations (K-MMSE).

Statistical analysis: Statistical analysis was performed by Statistical Package for the Social Sciences (SPSS) version 11.0 for statistical analysis. Differences in constipation scores, Bristol stool form scale, colon transit times, and location of brain injury were analyzed through an independent $\mathrm{t}$-test and the statistical significance level was $\mathrm{p}<0.05$.

\section{RESULTS}

\section{Defecation patterns of the study subjects}

The number of patients in the constipation group and the non-constipation group was 29 and 26, respectively, and the average age was $61.6 \pm 12.1$ and $60.6 \pm 16.2$, respectively. The number of patients who defecated less than 3 times per week in the constipation group was $14(48.3 \%)$ and $2(7.7 \%)$ in the non-constipation group. In the constipation group, 15 (51.7\%) reported straining during defecation vs. $6(23.1 \%)$ in the non-constipation group, and $13(44.8 \%)$ and $4(15.4 \%)$, respectively, had hard stools. Eight patients $(27.6 \%)$ in the constipation group and 3 patients (11.5\%) in the non-constipation group reported the sensation of incomplete evacuation, and 12 (41.4\%) and $4(15.4 \%)$, respectively, reported the need for manual maneuvers to facilitate defecation. In the constipation group, $21(72.4 \%)$ and $22(84.6 \%)$ in the non-constipation group reported that they defecated in a normal way, while the others used additional ways such as suppository, enema, and digital rectal stimulation. Bowel incontinence was observed in 1 patient in the constipation group and 3 patients in the non-constipation group, and $13(44.8 \%)$ and 9 (34.6\%), respectively, used a laxative. Total constipation scores ranged from 2 to 14 , average $6.27 \pm 3.32$, and the score was $7.32 \pm 3.63$ in the constipation group and $5.04 \pm 2.46$ in the non-constipation group; thus, significantly higher scores were observed in the constipation group. The stool form types ranged from 1 to 6 ; the type was $3.25 \pm 1.08$ in the constipation group and $4.21 \pm 1.10$ in the non-constipation group, showing significant differences between the 2 groups $(p<0.05)$ (Fig. 1). 
Table 3. The Results of Colon Transit Time between Constipation and Non-constipation Group

\begin{tabular}{lccccc} 
& $\mathbf{N}$ & Rt. colon & Lt. colon & Rectosigmoid colon & Total \\
\hline Constipation group & 29 & $14.48 \pm 11.82$ & $19.99 \pm 13.64$ & $12.11 \pm 12.34$ & $46.59 \pm 18.72$ \\
Non-constipation group & 26 & $8.31 \pm 8.42^{*}$ & $9.37 \pm 11.01^{*}$ & $14.60 \pm 16.24$ & $32.28 \pm 23.54^{*}$ \\
\hline
\end{tabular}

Each value was expressed by Mean \pm SD

Statistical analysis was performed by independent samples t-test using SPSS version 11 (Chicago Inc., Chicago, USA)

*Denotes significant difference between the constipation and non-constipation groups $\left({ }^{*} \mathrm{p}<0.05\right)$

(A)

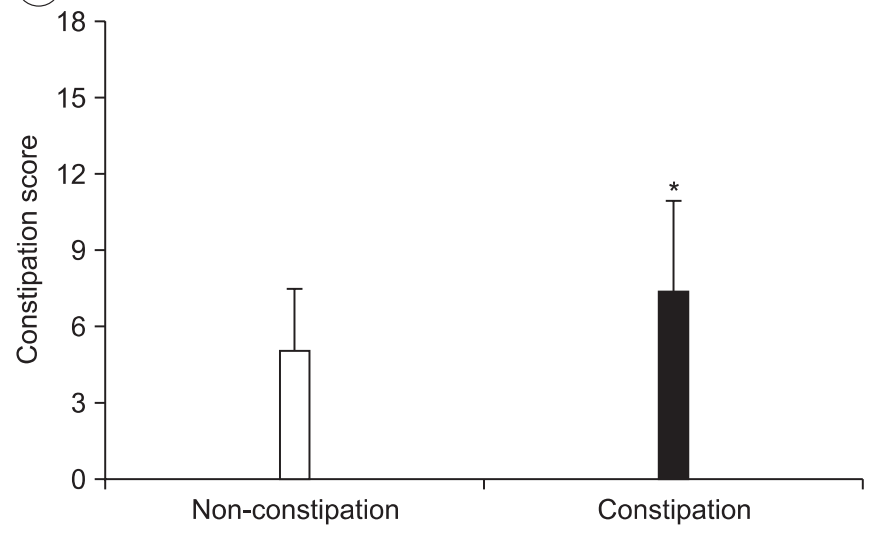

(B)

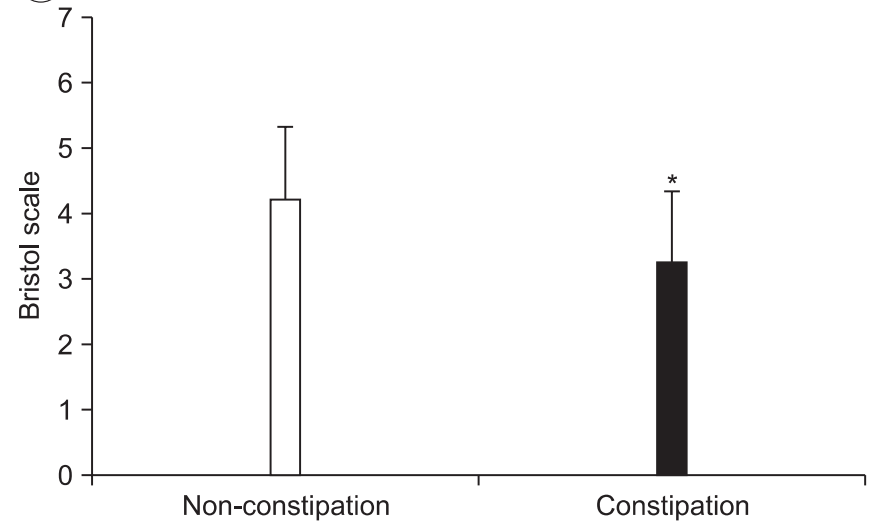

Fig. 1. The comparison of constipation score and Bristol scale in constipation and non-constipation group. Values are expressed mean \pm SD. *Denotes significant difference between constipation and non-constipation group ( $\left.{ }^{*} \mathrm{p}<0.05\right)$.

\section{Colon transit time}

The CTTs in the constipation group and the nonconstipation group were $46.6 \pm 18.7 \mathrm{~h}$ and $32.3 \pm 23.5 \mathrm{~h}$, respectively, showing that CTT was significantly delayed in the constipation group $(\mathrm{p}<0.05)$. The segmental CTTs in the constipation group and the non-constipation groups were $14.5 \pm 11.8 \mathrm{~h}$ and $8.3 \pm 8.4 \mathrm{~h}$ in the right colon, and 20.0 $\pm 13.6 \mathrm{~h}$ and $9.4 \pm 11.0 \mathrm{~h}$ in the left colon, respectively, significantly delayed in the constipation group $(\mathrm{p}<0.05)$; however, segmental CTTs in the rectosigmoid colon were $12.1 \pm 12.3 \mathrm{~h}$ and $14.6 \pm 16.2 \mathrm{~h}$, respectively, showing no significant difference between the 2 groups (Table 3, Fig. 2).

Correlation between the site of brain injury and colon transit time

The CTT of patients who had pontine injury and those who had suprapontine injury was $45.1 \pm 20.1 \mathrm{~h}$ and $38.7 \pm 22.6 \mathrm{~h}$, respectively, showing no statistically significant difference, and segmental CTT was $11.8 \pm 9.3 \mathrm{~h}$ and $11.5 \pm 11.1 \mathrm{~h}$, respectively, in the right colon, $22.3 \pm 13.4$ $\mathrm{h}$ and $13.3 \pm 13.1 \mathrm{~h}$, respectively, in the left colon, and

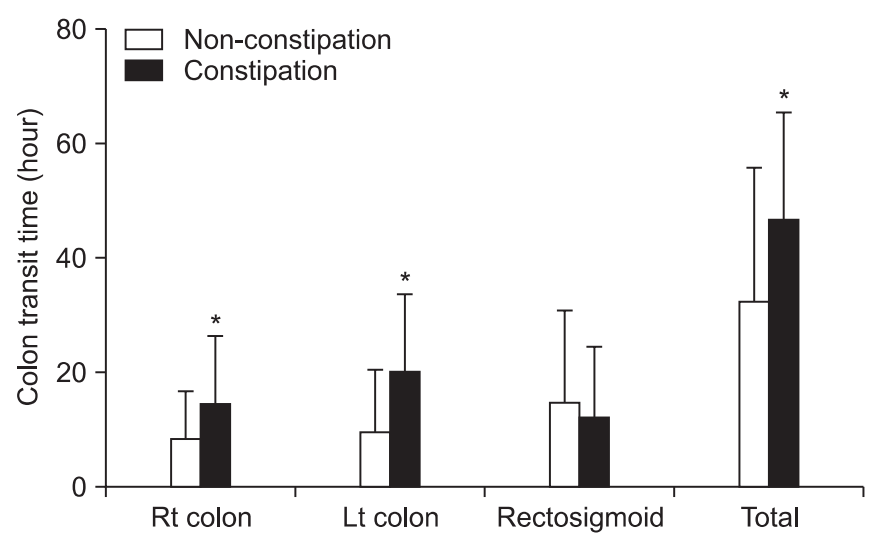

Fig. 2. The results of total and segmental colon transit time between constipation and non-constipation group. Values are expressed mean \pm SD. *Denotes significant difference between constipation and non-constipation group in right, left and total colon transit time $\left({ }^{*} \mathrm{p}<0.05\right)$.

$11.0 \pm 9.5 \mathrm{~h}$ and $13.8 \pm 15.1 \mathrm{~h}$, respectively, in the rectosigmoid colon, showing significantly delayed time only in the left colon among those who had pontine injury $(\mathrm{p}<0.05)$ (Table 4, Fig. 3). 
Table 4. The Results of Colon Transit Time between Suprapontine and Pontine Lesion Group

\begin{tabular}{lrlccc}
\hline & N & Rt. colon & Lt. colon & Rectosigmoid colon & Total \\
\hline Suprapontine lesion & 45 & $11.52 \pm 11.10$ & $13.33 \pm 13.07$ & $13.80 \pm 15.12$ & $38.66 \pm 22.61$ \\
Pontine lesion & 9 & $12.96 \pm 8.39$ & $25.56 \pm 13.23^{*}$ & $12.08 \pm 8.73$ & $50.60 \pm 15.65$ \\
\hline
\end{tabular}

Each value was expressed by Mean \pm SD

Statistical analysis was performed by independent samples t-test using SPSS version 11 (Chicago Inc., Chicago, USA)

${ }^{*}$ Denotes significant difference between the suprapontine and pontine lesion groups $\left({ }^{*} \mathrm{p}<0.05\right)$

(A)

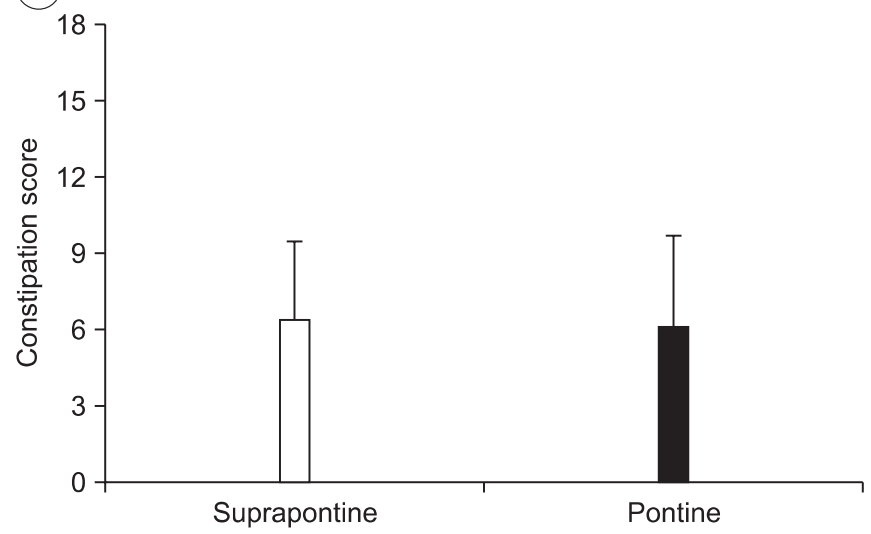

(B)

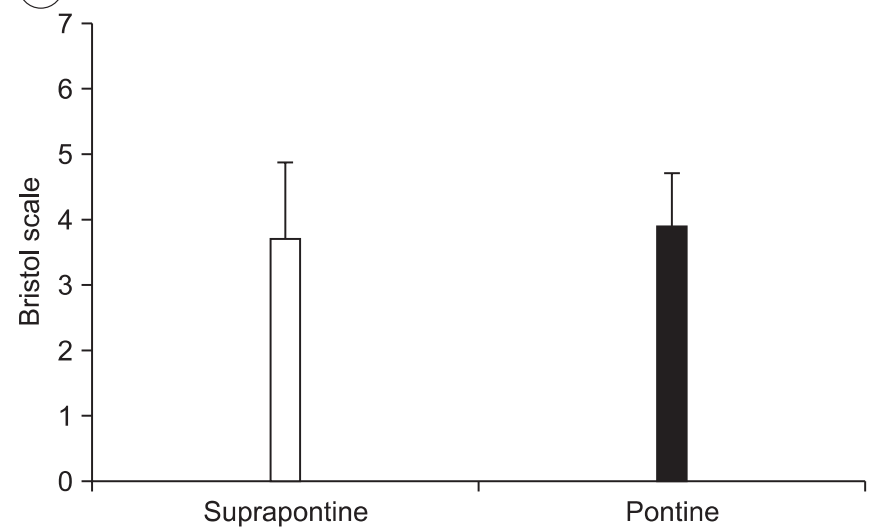

Fig. 3. The comparison of constipation score and Bristol scale between suprapontine and pontine lesion group. Values are expressed mean \pm SD. There was no significant difference in constipation score and Bristol scale.

Correlation between the site of brain injury and defecation patterns

Constipation scores in the pontine lesion group and suprapontine lesion group were $6.00 \pm 3.71$ and $6.27 \pm 3.24$, respectively, showing no statistically significant difference between the 2 groups, and the Bristol stool form scale were $3.55 \pm 1.24$ and $3.69 \pm 1.19$, respectively, showing no statistically significant difference between the 2 groups (Fig. 4).

\section{Correlation between CTT and FIM, and K-MMSE}

FIM of the constipation group and the non-constipation group was $81.2 \pm 22.7$ and $92.0 \pm 23.7$, respectively, showing no significant difference between the 2 groups, but when comparing sub-divided items, the scores for movement were $12.7 \pm 5.9$ and $15.5 \pm 5.3$ and the scores for ambulation were $7.1 \pm 4.3$ and $8.5 \pm 3.9$, respectively, showing significant difference between the groups. The K-MMSE scores were $22.7 \pm 6.2$ and $22.4 \pm 7.4$, showing no significant difference between the 2 groups.

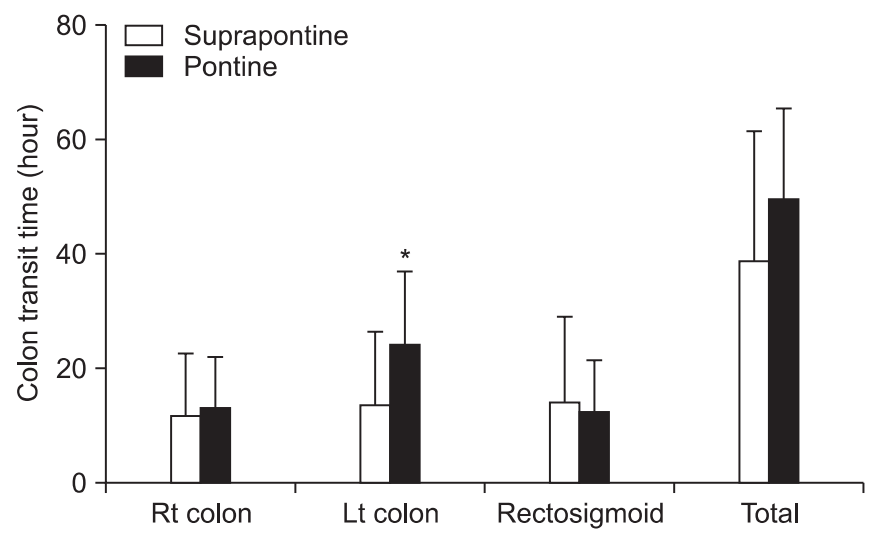

Fig. 4. The results of total and segmental colon transit time between suprapontine and pontine lesion group. Values are expressed mean \pm SD. *Denotes significant difference between suprapontine and pontine lesion group in left colon transit time $\left({ }^{*} \mathrm{p}<0.05\right)$.

\section{DISCUSSION}

Usually, the definition of constipation is based on less than 3 times per week, but recent studies have reported that constipation should be considered with regard to 
hardness of stools, level of dryness, size of stools, and difficulties and straining in defecation, as well as the frequency of defecation. ${ }^{13}$ This study divided brain-injured patients into constipation and non-constipation groups using the Rome II criteria and assessed the correlation between constipation score, Bristol stool form scale, and CTT. The constipation score assessed the frequency and degree of the 6 items of the Rome II criteria that are symptoms of functional constipation, and a higher score meant more severe constipation. The stool form scale was introduced by Davies et al. ${ }^{14}$ in 1986 and is used as a simple way to estimate the CTT of outpatients. The Bristol stool form scale was introduced ${ }^{11}$ to solve a problem with the stool form scale and describe the stool forms in the flushing toilet, and Degen and Phillips ${ }^{15}$ proved the validity of the Bristol stool form scale in estimating CTT. In this study, the constipation score of the constipation group was significantly higher than that of the non-constipation group, and the Bristol stool form scale of the constipation group were significantly lower than those of the nonconstipation group. There may be correlation between a patient's subjective symptoms using the Rome II criteria and the Bristol stool forms scale, and it is thought that the constipation score reported by patients or their guardians and the Bristol stool form scale can be used as an index for assessment of defecation disorder.

Colon transit time is a relatively easy and simple method for assessing the colonic motility, and the presence of constipation symptoms has a significant relation to delayed CTT. It is reported that the average CTT measured by the 4-day method using Kolomark ${ }^{\circledR}$ among asymptomatic Korean adults is $19.3 \pm 18.3 \mathrm{~h}^{16}$ and $10.6 \pm 12.8 \mathrm{~h}$ using Sitzmark. ${ }^{17}$ The present study found that total CTT in the constipation group was $46.59 \pm 18.72 \mathrm{~h}$, a statistically significant increase when compared with the nonconstipation group. This result corresponds to another report that demonstrated that the total and segmental CTT was delayed in the constipation group of acute brain injury patients compared with the non-constipation group $^{8}$ and a report that the total and segmental CTTs among adult patients with spastic cerebral palsy was delayed. ${ }^{6}$ Considering previous reports that brain injury causes problems of functional adjustment leading to decline of gastrointestinal motility, ${ }^{1}$ it is thought that brain injury may partly influence the decline of motility of visceral smooth muscles. While the segmental CTTs of the constipation group were significantly delayed in the right and left colon, there was no significant difference in the rectosigmoid colon between the constipation group and the non-constipation group. We believe the reason for this is that while functional constipation in the absence of neurologic abnormality ${ }^{18}$ is related to rectal area stasis, brain-injured patients show delays of CTT more frequently around the proximal colon, and after brain injury, they may lose neurologic modulation of enterokinesia. ${ }^{19}$ Further, because all of the study subjects were patients who underwent various hospital treatments, received appropriate defecation management education, and were under defecation management programs, it is thought that they could stimulate defecation around the rectosigmoid colon through appropriate defecation management techniques.

The duration of injury of the study subjects ranged from 21 days to 54 months, averaging $11.1 \pm 17.5$ months. As in a previous study targeting acute stroke patients who had acquired their injuries about 13 days before, ${ }^{8}$ the CTT in the constipation group was significantly delayed in the ascending, descending, and total colon compared with that of the non-constipation group. Thus, it appears that it is necessary to start bowel management early after the brain injury and to sustain the management continuously. In addition, we propose that it will be necessary to conduct additional studies about bowel dysfunction with regard to the duration of time after the initial brain injury.

When pontine or suprapontine regions are damaged due to brain injury, a problem of reduced gastrointestinal motility may arise which or may arise in the modulation of the defecation reflex arch, and because of this, patients are expected to have some difficulties in managing regular defecation. However, plenty of controversy remains over the normal defecation mechanism and its modulation by the central nervous system. Barrington's nucleus has been known as the pontine micturition center (PMC), and in 1998, Pavcovich et al. ${ }^{20}$ reported that chemical stimuli of Barrington's nucleus increased luminal pressure of the colon, especially the distal colon, suggesting that the pons has an important influence on modulating the activity of forebrain and on colonic motility. Though it has been found previously that there is no difference in the frequency of defecation according to the area of brain injury, ${ }^{3}$ there are few studies examining the correlation 
between the area damaged in the cerebral hemisphere by the brain injury, and and bowel dysfunction. The present study compared defecation patterns and stool form characteristics among patients classified by area of brain injury into a pontine lesion group and a suprapontine lesion group. There was no significant difference between the 2 groups, except for the left colon segmental CTT delay in the pontine lesion group. Although it is not possible to conclude that pontine lesions cause greater decline of colonic motility than the suprapontine lesions with our results, it is thought that pontine lesions as well as damage to the primary motor and sensory cortices may have influences on changes in colonic motility. It will be necessary to conduct future studies focused on the changes in colonic motility according to the site of brain injury.

Another study of the factors influencing constipation reported that CTTs in pediatric patients with quadriplegic cerebral palsy who were not able to ambulate were delayed and suggested that a decline in motility has a great influence on constipation. ${ }^{7}$ When assessing the correlation between CTT and FIM in this study, there was no statistical difference, but the constipation group showed a significantly lower score in transfer and ambulation among sub-items for assessing motor skills. Additional studies will be required in the future to provide a quantitative evaluation of ambulation ability and physical activity.

This study had limitations. The study that did not adjust for various diseases other than brain injury which may influence defecation; further, the number of subjects in the pontine lesion group was not sufficient. The study did not represent bowel dysfunction of all brain injured patients because when a patient was unable to swallow the Kolomark $^{\circledR}$ due to severe dysphagia, it was not possible to attain a CTT, thereby the patients were excluded from the study population. Also, although previous studies ${ }^{8}$ have reported that there was no difference in the amount of intake of water and food or medications used between constipation groups and the non-constipation groups, our study could not control for the level of intake of water and food fiber and various medications that may have influenced colonic motility. Each of these limitations could be utilized in future studies. As well, it will be necessary to conduct future studies about the neural mechanisms of regulation of colonic motility and its correlations to overcome such limitations.

\section{CONCLUSION}

In this study targeting 55 brain-injured patients, the constipation group showed high constipation scores and low Bristol stool form scale and had delayed colon transit times in the total, right, and left colon. When classified based on the area of brain injury, there was no significant difference in constipation score, Bristol stool form scale, or CTT between the pontine lesion group and the suprapontine lesion group.

\section{ACKNOWLEDGEMENTS}

This paper was supported by Wonkwang University in 2011.

\section{REFERENCES}

1. Bracci F, Badiali D, Pezzotti P, Scivoletto G, Fuoco U, Di Lucente L, Petrelli A, Corazziari E. Chronic constipation in hemiplegic patients. World J Gastroenterol 2007; 13: 3967-3972

2. Robain G, Chennevelle JM, Petit F, Piera JB. Incidence of constipation after recent vascular hemiplegia: a prospective cohort of 152 patients. Rev Neurol (Paris) 2002; 158: 589-592

3. Min KC, Chong SY, Chung JS. A survey of defecation pattern after discharge in stroke patients. J Korean Acad Rehab Med 2000; 24: 388-394

4. Ashraf W, Park F, Lof J, Quigley EM. An examination of the reliability of reported stool frequency in the diagnosis of idiopathic constipation. Am J Gastroenterol 1996; 91: 26-32

5. Im SH, Rah UW, Lee IY, Cho KH. Colon transit time and management of upper motor neuron type neurogenic bowel in spinal cord injury. J Korean Acad Rehab Med 2000; 24: 446-452

6. Park ES, Park CI, Cho SR, Na SI, Kwark EH, Noh KN. Assessment of colonic motility and nutrients intake in adult with cerebral palsy. J Korean Acad Rehab Med 2003; 27: 192-197

7. Park ES, Park CI, Cho SR, Park SY, Cho YS. Assessment of colonic motility and nutrients intake in children with spastic cerebral palsy. J Korean Acad Rehab Med 2002; 26: 19-25

8. Yi JH, Chun MH, Kim BR, Han EY, Park JY. Bowel func- 
tion in acute stroke patients. Ann Rehabil Med 2011; 35: 337-343

9. Thompson WG, Longstreth GF, Drossman DA, Heaton KW, Irvine EJ, Miler-Leissner SA. Functional bowel disorders and functional abdominal pain. Gut 1999; 45 suppl 2: II43-47

10. Cheon JH, Yoon IJ, Myung SJ, Byeon JS, Ko JE, Jung KW, Kim B, Kwon SH, Do MY, Kim DH, et al. Use of constipation remedies not prescribed by physician - a study of patients at a constipation clinic. Kor J Neurogastroenterol Motil 2007; 13: 45-52

11. O'Donnell LJ, Virhee J, Heaton KW. Detection of pseudodiarrhoea by simple clinical assessment of intestinal transit rate. BMJ 1990; 300: 439-440

12. Arhan P, Devroede G, Jehannin B, Lanza M, Faverdin C, Dornic C, Persoz B, Tetreault L, Perey B, Pellerin D. Segmental colonic transit time. Dis Colon Rectum 1981; 24: 625-629

13. Kwon HK, Do HJ, Kim HJ, Oh SW, Lym YL, Choi JK, Joh HK, Kweon HJ, Cho DY. The impact of functional constipation on the quality of life in the elderly over 60 years. Korean J Farm Med 2010; 31: 35-43

14. Davies GJ, Crowder M, Reid B, Dickerson JW. Bowel function measurements of individuals with different eating patterns. Gut 1986; 27: 164-169

15. Degen LP, Phillips SF. How well does stool form reflect colonic transit? Gut 1996; 39: 109-113

16. Suh SW, Park HJ, Jung HY, Rhee JC, Rhee PL, Kim JJ, Paik SW, Choi KW, Lee JH, Koh KC, et al. Comparison of 4-day and 7-day methods in the evaluation of colon transit time. Korean J Gastroenterol 2001; 38: 241-246

17. Yoo SK, Nah YH. Colonic transit time in healthy Korean. Korean J Gastroenterol 1990; 22: 535-539

18. Corazziari E, Cucchiara S, Staiano A, Romaniello G, Tamburrini O, Torsoli A, Auricchio S. Gastrointesinal transit time, frequency of defecation, and anorectal manometry in healthy and constipated children. J Pediatr 1985; 106: 379-382

19. Del Guidice E, Staiano A, Capano G, Romano A, Florimonte L, Miele E, Ciarla C, Campanozzi A, Crisanti AF. Gastrointestinal manifestations in children with cerebral palsy. Brain Dev 1999; 21: 307-311

20. Pavcovich LA, Yang M, Miselis RR, Valentino RJ. Novel role for the pontine micturition center, Barringtos's nucleus: evidence for coordination of colonic and forebrain activity. Brain Res 1998; 784: 355-361 